$>$ Distribution of equal amount of water at right time by automatic irrigation to farm and nurseries.

$>$ To avoid unnecessary of overwatering at the wrong time of the day, this reduces saturated soils which will improve crop performance.

$>$ Automated irrigation system uses valves to turn motor ON and OFF. Motors can be easily automated using controllers which reduces labor work.

$>$ These method for irrigation is valuable tool for accurate soil moisture control in highly specialized greenhouse vegetable production.

\subsection{PROBLEM STATEMENT}

To design and develop automatic irrigation system that switches a motor pump ON/OFF by sensing moisture content of the soil through application of Internet of Things (IOT).

\section{LITERATURE SURVEY}

The birth of internet in 1989, since then connecting "Things" in the internet began widely in use.

Trojan Room Coffee pot is possibly the first application of this kind [1].

1990, John Romkey developed a first internet 'device' [2], a toaster that could be turned on and off over the internet [3].

Paul Saffo's [4] gave the first brief description of sensors and their future course of action in 1997.

Sensors are deployed everywhere and these sensors convert raw physical data into digital signals and transmits them to its control center [5].

The term Internet of Things was coined by Kevin Ashton, RFID-based item identification system was also invented in the same year [6].

Dr. V. Vidya Devi, G. Meena kumari, "Real-Time Automation and Monitoring System for Modernized Agriculture", Temperature moisture level was sensed for unpredictable environment present a need of proper utilization of water [7].

Juan Francisco Villa-Medina, Alejandra NietoGaribay, Web pages programmed through inspection and irrigation scheduling for the system that is powered by photovoltaic panels and have duplex communication link based on a cellular internet interface, have algorithm developed with threshold values of temperature and soil moisture can be programmed into a microcontroller based gateway to control water quantity [8].

Y. Kim, a system was developed where its main objective was using distributed wireless sensor network aiming for variable rate irrigation, real time in field sensing, controlling of a site specific precision linear move irrigation system to maximize the producing with minimal use of water [9].

R. Suresh, S. Gopinath, K. Govindaraju, T. Devika, N. Suthanthira Vanitha developed. GSM based automated irrigation control using rain gun where irriagation will be intense requirement of water that save a large quantity of water [10].

Pavithra D. S, M. S Srinath developed a system GSM based on Automatic Irrigation Control System for Efficient use of Resources and crop planning by using an Android Mobile.

System with GSM (RS-232) module used to supports monitoring and water management decisions.

Power growth of plant can be checked by checking temperature and humidity of soil which retain the nutrient composition of the soil.

[11], Laxmishabadi, Nandini Patil, Nikita. M, Shruti, Smitha. P and Swati. C, an Irrigtion Control System Using Android and GSM for efficient use of water and power where in turn system uses Valves to turn motor $\mathrm{ON}$ and $\mathrm{OFF}$, using controllers these valves may be easily automated.

Remote Sensing and Control of an Irrigation System Using Distributed Wireless Sensor Network Yunseop (James) kim, Robert G. Evans, and William M Iversen setup a technical system which is based on relatively an efficient system that has developed windows application to monitor the field. Microcontroller Based Automatic Plant Irrigation System, Venkata Naga Rohit Gunturi, system. The system microcontroller which is programmed for giving interrupt signals to the sprinkler.

\section{PROPOSED DESIGN METHODOLOGY 3.1 PROPOSED SYSTEM}

Agriculture field nowadays facing lot of problem due to lack of water resources. In order to work on the 
difficulties, smart irrigation system has been used in which various sensors such as $\mathrm{pH}$ sensor, soil moisture sensor, temperature sensor where in our project we are using soil moisture sensor which is connected to the pins of arduino microcontroller. The sensed values are stored in Adafruit server, if the sensed values is 1 the water pump will be automatically switched ON and OFF upon value 0 . By using these, system the farmer can access the details about the condition of the field anywhere at any time.

\subsection{PROPOSED SYSTEM ARCHITECTURE}
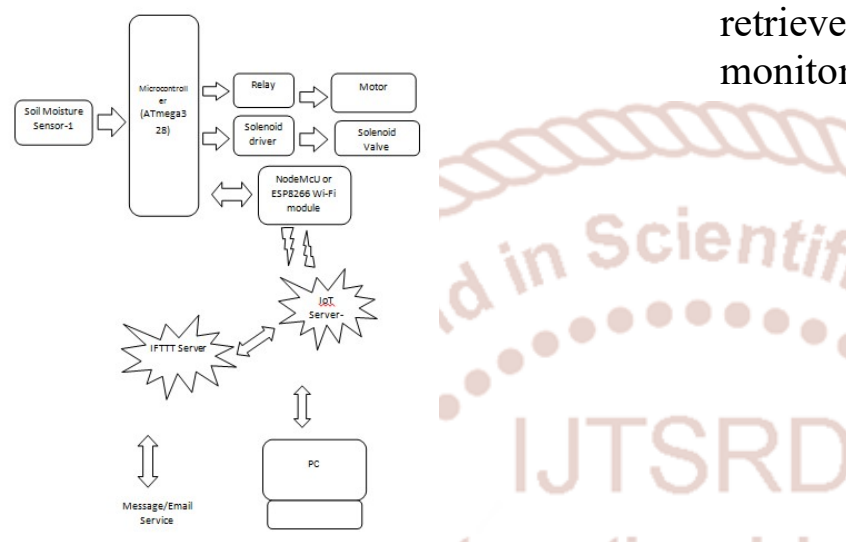

Figure 3.1: Block Diagram of Smart Irrigation System.
Software Requirement:

Arduino IDE

\section{RESULTS AND DISCUSSION}

Developed system is tested under various conditions. The soil moisture test the soil for all climatic conditions and results are interpreted successfully. The moisture reading at different weather conditions is taken and updated. The wireless transmission was achieved using Wi-Fi.

The data is stored in Adafruit server, the data is then retrieved successfully from Adafruit which is used for monitoring purpose.

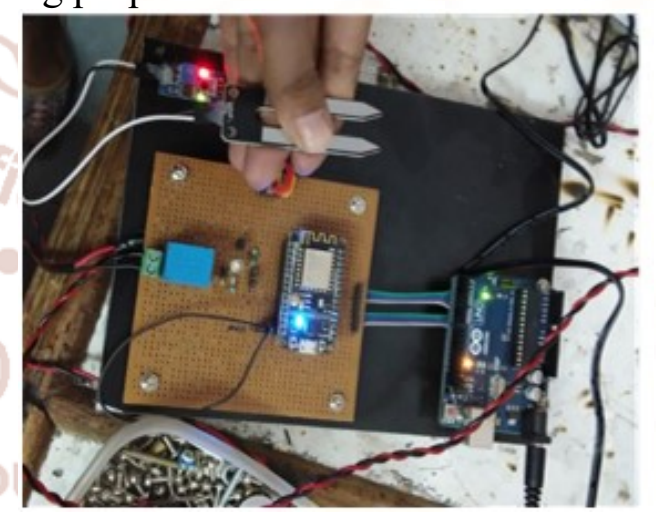

Figure 4.1: Soil Moisture Sensor when value is 0

The block diagram of smart irrigation system compares main components namely such as arduino, nodeMcU, soil moisture sensor, adafruit server, relay, $\bigcirc$ being the most wet condition. motor. When sensor circuit senses the condition of soil, it compares it with the reference voltage $5 \mathrm{v}$.

When the soil condition is less than the reference voltage that is $5 \mathrm{v}$, the soil is considered dry and instantly sends the logic signal to the microcontroller. The microcontroller then turns on the motor driver circuit and pump water to plants. If the sensed value is greater than reference voltage $5 \mathrm{v}$, the logic signal 0 is send to microcontroller, which turns off the motor driver circuit.

\subsection{HARDWARE \\ AND REQUIREMENT \\ SOFTWARE}

The hardware and the software tools essential for implementing this project are given below:

\section{Hardware Requirement:}

$>$ Arduino

$>$ NodeMcU

$>$ Relay

$>$ Solonoid

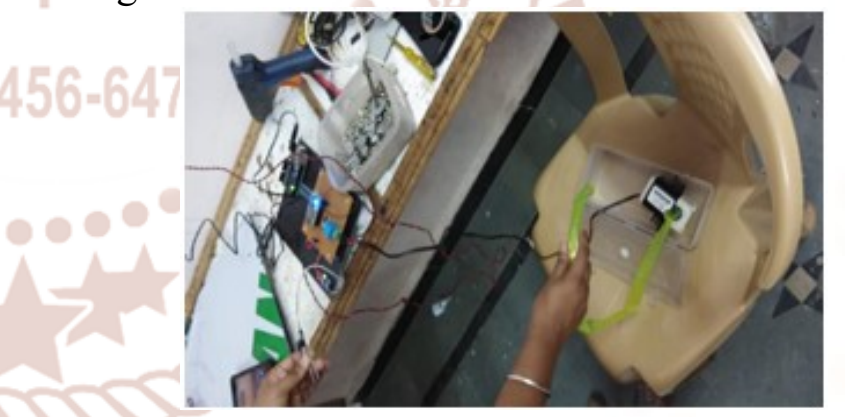

Figure 4.2: Motor pump OFF upon value is 0

The sensed value is send to microcontroller through NodeMcU and motor pump is OFF in this condition.

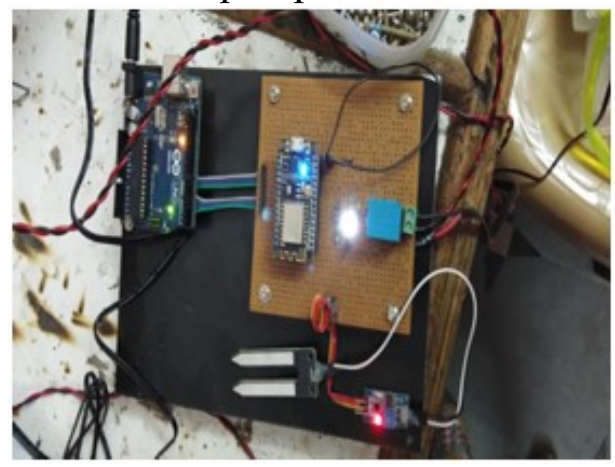

Figure 4.3: Soil moisture sensor when value is 1 
The maximum threshold value upon dry soil is 1023. When the sensed value by sensor reaches the threshold value microcontroller trigger the relay and motor is $\mathrm{ON}$.

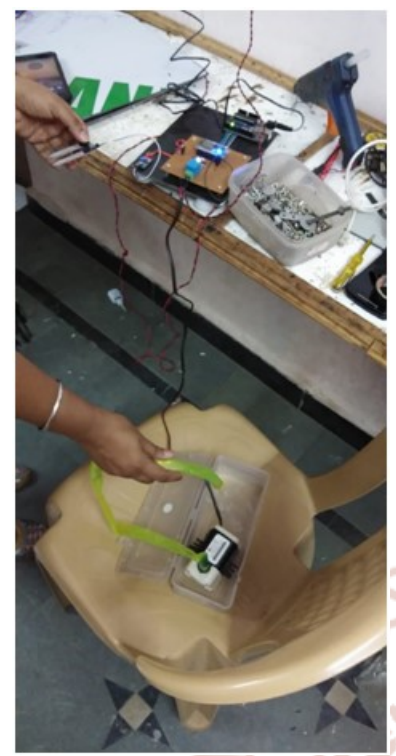

Figure 4.4: Motor pump ON upon value 1

Motor pump is turned $\mathrm{ON}$ and is turned $\mathrm{OFF}$ automatically when sufficient amount of water is supplied to plants.

\section{CONCLUSION AND FUTURE SCOPE}

The automation in irrigation system is appropriate and price adequate for accessing water source of supply for agriculture management. The regular updates to the server can get proper knowledge to the system and can work perfectly for indefinite time period. Human factor energy and power can be reduced.

\section{Project is used for the following}

$>$ Field is maintained by maintaining moisture level within the root zone.

$>$ Distribution of water in the field is uniform.

$>$ This irrigation method reduces labor cost.

$>$ Water and electricity consumption is reduced to significant amount.

\section{Future Work}

The project has tremendous scope in developing it and making it more user-friendly and with additional features like:

$>$ To capture the photos a webcam can be installed to the device, which can be sent to database.

$>$ Implementation of speech based option for those who are unable to read.

$>$ A device with a GPS can be integrated to provide specific location of the farmer and more accurate weather reports of agriculture field and garden.
All the features on device end can developed in the regional language, which helps in easy reading for the farmers.

\section{REFERENCES}

1. Vipul Gupta and David G. Simmons, Sun Labs, Oracle "Building the Web of Things with Sun SPOTs" Java One 2010, Hands-on Lab.

2. https://romkey.com.

3. http://wearcam.org/myview.html.

4. http://www.saffo.com/essays/sensors-the-nextwave-of InfoTech-Innovation.

5. Ross Yu, Thomas Watteyne "Reliable, Low Power Wireless Sensor Networks for the Internet of Things: Making Wireless Sensors as Accessible as Web Servers", white paper, LT 1213, (C) Linear Technology Corporation 2013.

6. http://www.rfidjournal.com/articles/view?4986.

7. S. R. Nandurkar, V. R. Thool, R. C. Thool, "Design and Development of Precision Agriculture System Using Wireless Sensor Network", IEEE International Conference on Automation, Control, Energy and Systems (ACES), 2014.

8. Joaquin Gutierrez, Juan Francisco Villa-Medina, Alejandra Nieto-Garibay, and Miguel Ángel Porta-Gándara, "Automated Irrigation System Using a Wireless Sensor Network and GPRS Module", IEEE TRANSACTIONS ON INSTRUMENTATION AND MEASUREMENT, 0018-9456,2013.

9. Y. Kim, R. Evans and W. Iversen, "Remote Sensing and Control of an Irrigation System Using a Distributed Wireless Sensor Network", IEEE Transactions on Instrumentation and Measurement, pp. 1379-1387, 2008.

10. Pavithra D. S, M. S. Srinath, "GSM based Automatic Irrigation Control System for Efficient Use of Resources and Crop Planning by Using an Android Mobile", IOSR Journal of Mechanical and Civil Engineering (IOSR-JMCE) Vol11, IssueI, Jul-Aug 2014, pp 49-55.

11. Laxmi Shabadi, Nandini Patil, Nikita. M, Shruti. J, Smitha. P \& Swati. C, "Irrigation Control System Using Android and GSM for Efficient Use of Water and Power", International Journal of Advanced Research in Computer Science and Software Engineering, Volume 4, Issue 7, July 2014. 